\title{
Optimizing total reflection X-ray fluorescence for direct trace element quantification in proteins I: Influence of sample homogeneity and reflector type
}

\author{
G. Wellenreuther ${ }^{\text {a }}$, U.E.A. Fittschen ${ }^{\text {b }}$, M.E.S. Achard ${ }^{\mathrm{a}, 1}$, A. Faust ${ }^{\mathrm{a}}$, X. Kreplin ${ }^{\text {a }}$, W. Meyer-Klaucke ${ }^{\mathrm{a}, *}$ \\ a European Molecular Biology Laboratory, Notkestr. 85, 22603 Hamburg, Germany \\ ${ }^{b}$ Department of Chemistry, University of Hamburg, Martin-Luther-King-Platz 6, 20146 Hamburg, Germany
}

\section{A R T I C L E I N F O}

\section{Article history:}

Received 1 November 2007

Accepted 8 October 2008

Available online $\mathrm{xxxx}$

\section{Keywords:}

Metalloprotein

Metal quantification

TXRF

$\mu \mathrm{XRF}$

Trace elements

\begin{abstract}
A B S T R A C T
Total reflection X-ray fluorescence (TXRF) is a very promising method for the direct, quick and reliable multielemental quantification of trace elements in protein samples. With the introduction of an internal standard consisting of two reference elements, scandium and gallium, a wide range of proteins can be analyzed, regardless of their salt content, buffer composition, additives and amino acid composition. This strategy also enables quantification of matrix effects. Two potential issues associated with drying have been considered in this study: (1) Formation of heterogeneous residues of varying thickness and/or density; and (2) separation of the internal standard and protein during drying (which has to be prevented to allow accurate quantification). These issues were investigated by microbeam X-ray fluorescence ( $\mu \mathrm{XRF}$ ) with special emphasis on (I) the influence of sample support and (II) the protein / buffer system used. In the first part, a model protein was studied on well established sample supports used in TXRF, PIXE and XRF (Mylar, siliconized quartz, Plexiglas and silicon). In the second part we imaged proteins of different molecular weight, oligomerization state, bound metals and solubility.

A partial separation of protein and internal standard was only observed with untreated silicon, suggesting it may not be an adequate support material. Siliconized quartz proved to be the least prone to heterogeneous drying of the sample and yielded the most reliable results.
\end{abstract}

(c) 2008 Elsevier B.V. All rights reserved.

\section{Introduction}

Trace elements are essential for organisms from all kingdoms of life. Pathogenic bacteria compete with their hosts for the limited amounts of essential elements, such as iron [1-3] and control of trace element availability may open new ways to fight bacterial diseases. This however requires an in-depth understanding of the steps involved in trace element homeostasis. Regardless of the great potential of such an approach today only in a limited number of studies accurate quantifications of the trace element content are available. Irrespective of the level, cellular or molecular, this limits future research, because in total, 20 to $30 \%$ of all proteins contain metals, either to stabilize protein structures, regulate gene expression, transport electrons or oxygen, induce protein activity or catalyze enzymatic reactions [4].

These days most proteins for research, irrespective of their origin, are expressed in genetically modified bacteria such as Escherichia coli.

is This paper was presented at the 12th Conference on Total Reflection X-ray Fluorescence Analysis and Related Methods held in Trento (Italy), 18- $\hat{2} 2$ June 2007, and is published in the Special Issue of Spectrochimica Acta Part B, dedicated to that conference.

* Corresponding author. Tel.: +49 4089902124; fax: +49 4089902149.

E-mail address: Wolfram@embl-hamburg.de (W. Meyer-Klaucke).

Now at School of Molecular and Microbial Sciences, University of Queensland, Brisbane, Australia.
Consequently metal sites are sometimes not correctly assembled, 43 because essential maturation proteins are lacking in E. coli [5]. 44 Moreover, the metal contents after isolation can vary from batch to 45 batch in amount and profile. At the same time, for research on isolated 46 proteins the knowledge of type and number of bound metals provides 47 valuable insights: for uncharacterized proteins certain metals can be 48 associated with potential protein functions, which provide a starting 49 point for further studies. For well-known proteins the exact metal 50 profile is essential to interpret biochemical, molecular biology as well 51 as structural data.

To become a routine tool for the determination of protein-bound 53 trace elements an analytical method has to fulfill several requirements: 54

(1) Sufficient sensitivity to detect metals for a wide range of protein 55 concentrations and protein buffers

(2) Capability of detecting all relevant elements in a single 57 measurement

(3) Requiring as few resources (e.g., time, manpower, money) as 59 possible

(4) Possibility for high sample throughput

(5) Quick measurement and evaluation

A method often used to analyze the elemental composition of 63 protein samples is microbeam Proton Induced X-ray Emission ( $\mu$ PIXE) 64 [4,6-8]. The advantages of $\mu$ PIXE are its multi-element detection 65 
capability and the utilization of the protein-intrinsic sulphur standard. Unfortunately, this elegant approach imposes several restrictions on the sample (e.g. protein must contain reasonable number of sulphur atoms, buffer components may not contain any sulphur, chlorine should be replaced by bromine, samples should be thin since the sulphur signal is easily affected by matrix effects). While it is possible to prepare special $\mu$ PIXE-samples fulfilling these requirements the common denominator for different biochemical, structural and spectroscopic experiments is lost. On the other hand $\mu$ PIXE is a spatial resolved technique and therefore able to overcome dust contaminations. But due to the scanning process the measurement takes considerable time and its evaluation typically requires expert knowledge.

An alternative to $\mu \mathrm{PIXE}$ is Total Reflection X-ray fluorescence (TXRF) (see [9] and references herein) which already has shown its potential for protein samples $[10,11]$. This technique allows multielement detection with a better sensitivity than $\mu$ PIXE: indeed, its lowest limits of detection (LLDs) are in the order of $\mathrm{pg} / \mu \mathrm{l}$ for elements with $Z>18$ (e.g. see Table 5-2 in [9]). Since TXRF is an integrating method, measurements require only a few seconds and easy online data evaluation gives immediate access to most biological relevant trace element concentrations, which allows for high-throughput operation.

In TXRF contaminations (e.g. by dust particles) cannot be directly detected as in $\mu$ PIXE. Nevertheless their occurrence can be identified by a statistical analysis of the spread of concentrations determined for aliquots of the same sample: Any measurement yielding significantly higher concentrations in a few elements than the others is most probably contaminated, and should be discarded from further evaluation. The utilization of an internal standard, added prior to the TXRF analysis requires the determination of the protein concentration prior to the measurement. The internal standard allows measuring an extremely wide range of protein samples virtually regardless of their buffer, salt concentration or amino acid composition, and hence reduces significantly the time between the protein purification and trace element quantification.

Moreover, access to an X-ray tube-based TXRF-instrument is typically easier than to $\mu \mathrm{PIXE}$, which requires a proton accelerator. Furthermore, the structural biology community already enjoys broad access to synchrotron radiation facilities, opening the possibility of synchrotron-based TXRF (SR-TXRF) with its advantages of increased flux and high polarization.

The typical protein sample is present in an aqueous solution, which simplifies preparation of samples (as opposed to powdered samples or protein crystals): The sample can be deposited onto a standard TXRF reflector, dried and analyzed. The procedure is simple and the analysis is precise in the presence of an internal standard. This makes TXRF a method of choice, however the homogeneity of dried samples might be critical for an accurate analysis [12,13]. Frequently the presence of salts in $\mathrm{mM}$ or $\mathrm{M}$ concentration is required to keep a protein in 115 solution. These salts form a major component of the dried residue that 116 will be analysed by TXRF. While drying, components of the sample, 117 either from the buffer, the internal standard or the protein itself, could 118 spatially separate (e.g., due to the formation of salt crystals, "coffee 119 rings" [14] or other aggregation processes). This would affect the 120 thickness of the dried residue, resulting in areas with varying coverage 121 (see Fig. 1) and/or components.

Decomposition of the sample followed by homogenization in 123 liquid could help to circumvent some of these problems, but is not 124 in line with the high-throughput we aim at. Thus an optimized 125 direct method is favoured: (a) sample inhomogeneities are re- 126 duced by careful selection of reflector material and surface coating, 127 (b) quantification procedure is developed to determine and 128 quantify matrix effects, and (c) risk of a separation of protein and 129 its metals vs. the internal standard is assessed by micro beam X-ray 130 fluorescence ( $\mu \mathrm{XRF})$ experiments.

The later experiments shed light on the influence of (I) different 132 sample supports and (II) of the protein and the buffer itself on sample 133 homogeneity. For (I) we have chosen Mylar ${ }^{\circledR}$ foil (DuPont, Wilmington 134 (Delaware), USA), siliconized quartz, silicon and Plexiglas as sample 135 supports, since they are being used in a variety of methods, including 136 XRF, $\mu$ XRF, TXRF and $\mu$ PIXE. Mylar foils are extensively used as sample 137 supports in $\mu$ PIXE and XRF since they cause almost no background 138 signal. Quartz reflectors are the standard sample support for TXRF due 139 to their very low surface roughness; but they are quite expensive and 140 we consider their time-consuming re-use as a disadvantage under the 141 aspect of achieving true high-throughput operation. Reflectors made 142 from Plexiglas are cheap enough to be used as single-shot sample 143 supports enabling high-throughput operation. Unfortunately, their 144 surface is rough compared to quartz. This triggered the analysis of 145 silicon wafers: They come with nearly perfect surface quality, and 146 several reflectors can be cut from a single wafer resulting in a potential 147 cost/reflector close to that of Plexiglas. The model protein is a member 148 of the metallo-beta-lactamase super family (hELAC1) from our recent 149 research project [15] which turned out to produce optically inhomo- 150 geneous droplets.

To elucidate the influence of the individual protein properties (II) 152 we studied in addition four commercially available metalloproteins of 153 different molecular weight, oligomerization state, bound metals and 154 solubility both on Mylar and siliconized quartz.

\section{Experimental}

\subsection{Sample preparation}

\subsubsection{Standard}

The X-ray absorption properties of a protein solution depend on a 159 variety of parameters (e.g. protein concentration, concentrations of 160

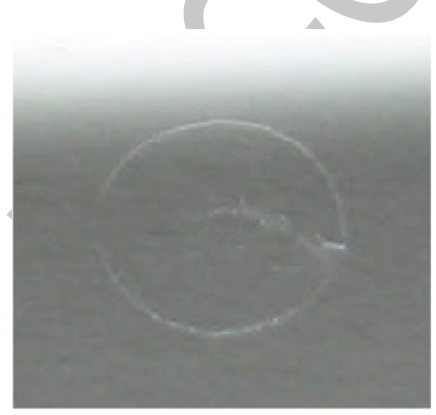

(a)

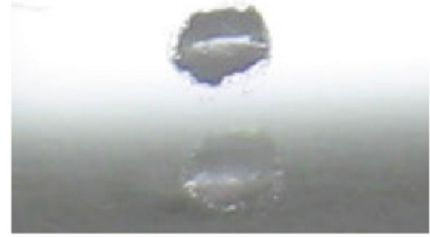

(b)

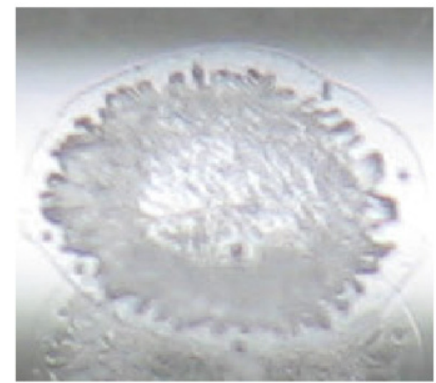

(c)

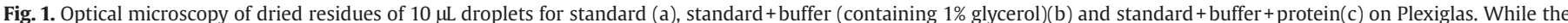

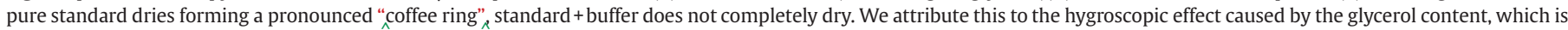

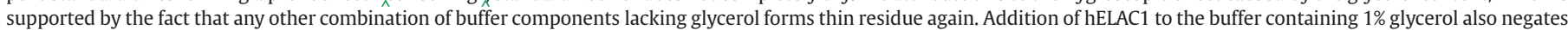
the negative effects of glycerol, as hELAC1 is strongly surface active. 
buffers / salts / additives) both directly (e.g. affecting the total absorption cross section of the dried solution) and indirectly (e.g. via changed dewetting properties, see Fig. 1). Hence, under highthroughput conditions any protein sample and/or its buffer might exhibit matrix effects. For its quantification we used two internal standards: scandium and gallium, whose $K_{\alpha}$ fluorescence energies, $4.09 \mathrm{keV}$ and $9.25 \mathrm{keV}$, differ considerably. Their strong difference in absorption makes it is possible to quantify matrix effects. For example, the transmission of $\mathrm{Sc}-K_{\alpha}$ through $100 \mu \mathrm{m}$ water (most protein samples predominantly consist of light elements with $Z<18$ ) is only $\sim 46 \%$, compared to $93.5 \%$ of $\mathrm{Ga}-\mathrm{K}_{\alpha}$ radiation.

In this work we refer as "standard" a solution containing $10 \mathrm{mg} / \mathrm{L}$ of scandium and $1 \mathrm{mg} / \mathrm{L}$ of gallium prepared by diluting standard solutions of gallium nitrate and scandium nitrate in 2-3\% HNO3 (Merck, Darmstadt standard for ICP-MS) into milliQ water. Adding this standard to the samples to be measured allows us to quantify the amount of matrix effects present in each sample individually, under the assumption that absorption of the Ga fluorescence may be neglected.

\subsubsection{Purified protein hELAC1}

Part I focuses on hELAC1, a Zn-dependent enzyme from the betalactamase superfamily; the cloning of the gene and purification of the protein has already been described in one of our previous work [15]. In brief, $h E L A C 1$ was cloned into an expression vector containing an $\mathrm{N}$ terminal His6 tag used for purification and the protein produced by E. coli containing this expression vector. The purification of hELAC1 from the bacteria was done in two steps: an affinity chromatography using a nickel-nitrilotriacetate (Ni-NTA) agarose binding the $\mathrm{His}_{6}$ tag of the protein and a gel filtration. At the final step, hELAC1 is pure and solubilized in the buffer used for gel filtration, which contains $20 \mathrm{mM}$ Tris/ $\mathrm{HCl} \mathrm{pH} 7.4,100 \mathrm{mM} \mathrm{NaCl}, 1 \%$ glycerol and $0.5 \mathrm{mM}$ Tris(2carboxyethyl)phosphine (TCEP). The concentration of purified hELAC1 is determined by measuring the absorption at $280 \mathrm{~nm}$ prior to addition of the standard solution. In this study, the concentration of hELAC1 is $15 \mu \mathrm{M}$. From now on, we will call "hELAC1" purified hELAC1 sample supplemented with $50 \%(\mathrm{v} / \mathrm{v})$ of standard and "buffer" gel filtration buffer samples supplemented with $50 \%(\mathrm{v} / \mathrm{v})$ of standard.

\subsubsection{Commercially available proteins}

The commercially available proteins used in part II were insulin [16,17], concanavalin A [18], thermolysin [18] and glucose isomerase [19] (see Table 1).

Insulin was dissolved in a buffer containing $2 \mathrm{mM} \mathrm{Na}_{2} \mathrm{PO}_{4}$ and $1 \mathrm{mM} \mathrm{Na} \mathrm{N}_{3}$ EDTA. According to the suppliers information the protein powder contains $\sim 0.5 \% \mathrm{Zn}$ which corresponds to $1 \mathrm{Zn}$ per protein. Concanavalin A (Lectin) was dissolved in milliQ water. Thermolysin, poorly soluble in water, was dissolved in $45 \%(\mathrm{v} / \mathrm{v})$ dimethyl sulfoxide (DMSO). Glucose isomerase was prepared from a crystal suspension of glucose isomerase by dialysis against milliQ water. The resulting sample was deprived of micro crystals. The natural metal cofactors of glucose isomerase are $\mathrm{Mn}$ (II) and $\mathrm{Mg}$ (II) but could be substituted by other divalent transition-metal ions [20].

\subsubsection{Reflectors and sample deposition}

212

The use of $\mathrm{nL}$ or even $\mathrm{pL}$ droplets has been proposed in order to 213 circumvent problems with spot inhomogeneities [13,21]: While $\mu \mathrm{L} 214$ droplets may dry inhomogenously, smaller droplets tend to be more 215 homogenous. In addition, nL droplets quickly dry in air, while 216 unassisted drying of $\mu \mathrm{L}$ droplets takes several hours. Increasing the 217 evaporation rate (e.g. by heating or vacuum drying) often causes 218 additional inhomogeneities [13]. This favours $\mathrm{nL}$ droplets from the 219 analytical point of view. Quartz reflectors commonly used as sample 220 carriers for TXRF were covered with a silicone layer by pipetting $10 \mu \mathrm{L} 221$ of a $10 \%$ silicone solution in isopropanol (Serva) onto the reflector and 222 heating at $120^{\circ} \mathrm{C}$ for one hour in order to create a hydrophobic surface 223 coating. Mylar foils of $0.6 \mu \mathrm{m}$ thickness were glued onto aluminium 224 frames. The silicon supports were cut in pieces of $24.7 \times 15.0 \mathrm{~mm}$ from 225 a silicon wafer (diameter $200 \mathrm{~mm}$ ) with the aid of a diamond saw. 226

Droplets were deposited by the Hydra II Plus One crystallization 227 robot which is part of the high-throughput crystallization facility at 228 EMBL Hamburg (Germany) [18]: The crystallization robot's micro- 229 pipette dispensed single droplets in the middle of each reflector. 230 Droplet volumes can be varied from several $\mu \mathrm{L}$ down to $100 \mathrm{~nL}$. In all 231 $\mu \mathrm{XRF}$ experiments $100 \mathrm{~nL}$ droplets were examined. In order to ensure 232 a sufficiently high signal to background ratio for TXRF measurements 233 it was necessary to use $500 \mathrm{~nL}$ droplets here. Samples dried within 234 several minutes in covered surroundings to prevent contamination. 235 Thus, drying of the samples is no longer the limiting time factor as 236 opposed to manually preparing samples.

\subsection{Setup}

Both the TXRF as well as the $\mu$ XRF-measurements were carried out 239 using $18.3 \mathrm{keV}$ X-rays monochromatized by the Ni/C-multilayer 240 system. The TXRF measurements were performed at HASYLAB 241 beamline L (Hamburg, Germany) in a vacuum chamber as described 242 in $[22,23]$. A peltier-cooled silicon drift detector (VORTEX, SII 243 NanoTechnology, Northridge, USA) with $50 \mathrm{~mm}^{2}$ active area collected 244 emitted fluorescence under an angle of $90^{\circ}$ to the incident X-ray beam 245 in plane with the synchrotron. This reduces the scattering background 246 due to the polarization of the incident beam.

For $\mu \mathrm{XRF}$ a polycapillary lens focused the beam down to $\sim 15 \mu \mathrm{m} 248$ FWHM [24]. Samples were mounted on a standard $\mathrm{x}-\mathrm{y}-\mathrm{Z}$-translation 249 stage under $45^{\circ}$ to both, the incident beam and the fluorescence 250 detector. An optical microscope was included for adjustment and 251 documentation.

\subsection{Measurements}

For TXRF the sample spots on the reflectors were vertically aligned 254 followed by an angle scan to tune into total reflection. TXRF-spectra 255 were taken for $100 \mathrm{~s}$ per sample, typically at angles around $30 \%$ of the 256 critical angle.

For $\mu \mathrm{XRF}$ the elemental maps were measured on a single droplet 258 considered representative judging from the optical microscope read- 259 ings. Measuring times per pixel varied from $10 \mathrm{~s}$ (for hELAC1 on 3-mm 260

\section{t1.1 Table 1}

Properties of commercial available proteins studied in this work

\begin{tabular}{|c|c|c|c|c|c|c|}
\hline & Molecular mass & Bound metals & Oligomeric state & Buffer & Concentration & Obtained from \\
\hline Insulin [16,17] & $\begin{array}{l}5.7 \mathrm{kDa} \\
51 \text { amino acids }\end{array}$ & $1 \mathrm{Zn}$ per monomer & monomer & $\begin{array}{l}2 \mathrm{mM} \mathrm{Na}_{2} \mathrm{PO}_{4} \\
1 \mathrm{mM} \mathrm{Na}{ }_{3} \mathrm{EDTA}\end{array}$ & $20 \mathrm{mg} / \mathrm{mL}$ & $\begin{array}{l}\text { Bovine pancreas } \\
\text { (Fluka Cat. No. } 57590 \text { Lot. No. S30941 355) }\end{array}$ \\
\hline $\begin{array}{l}\text { Concanava-lin A } \\
\text { (Lectin) [18] }\end{array}$ & $\begin{array}{l}25.6 \mathrm{kDa} \\
237 \text { amino acids }\end{array}$ & Mn & Homo-tetrameric & milliQ water & $25 \mathrm{mg} / \mathrm{mL}$ & $\begin{array}{l}\text { Canvalia ensiformis } \\
\text { (Fluka Cat. No. } 61760 \text { Lot No. } 114223710607351 \text { ) }\end{array}$ \\
\hline Thermolysin [18] & $\begin{array}{l}37.5 \mathrm{kDa} \\
316 \text { amino acids }\end{array}$ & $\begin{array}{l}1 \mathrm{Zn}+ \\
4 \mathrm{Ca} \text { per monomer }\end{array}$ & Homo-dimeric & $\begin{array}{l}45 \%(v / v) \text { dimethyl } \\
\text { sulfoxide (DMSO) }\end{array}$ & $20 \mathrm{mg} / \mathrm{mL}$ & $\begin{array}{l}\text { Bacillus thermoproteo-lyticus } \\
\text { (Calbiochem Cat No. 58656, Lot. No. B66938) }\end{array}$ \\
\hline $\begin{array}{l}\text { Glucose } \\
\text { isomerase [19] }\end{array}$ & $\begin{array}{l}43.1 \mathrm{kDa} \\
387 \text { amino acids }\end{array}$ & $\begin{array}{l}\text { Natural: } \mathrm{Mn}(\mathrm{II})+\mathrm{Mg}(\mathrm{II}) \\
\text { substitutions possible [20] }\end{array}$ & Homo-tetrameric & milliQ water & $20 \mathrm{mg} / \mathrm{mL}$ & $\begin{array}{l}\text { Streptomyces rubiginosus } \\
\text { (Hampton Research Cat. No. HR 7-102 Lot } \\
\text { No. 020606) }\end{array}$ \\
\hline
\end{tabular}



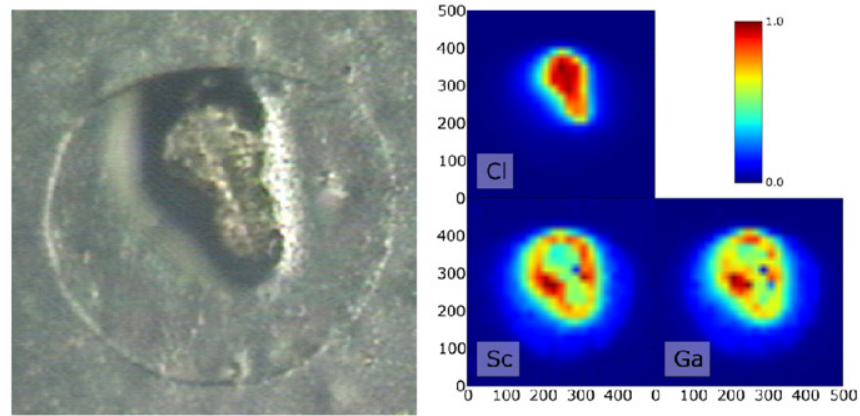

(a) Buffer on Mylar
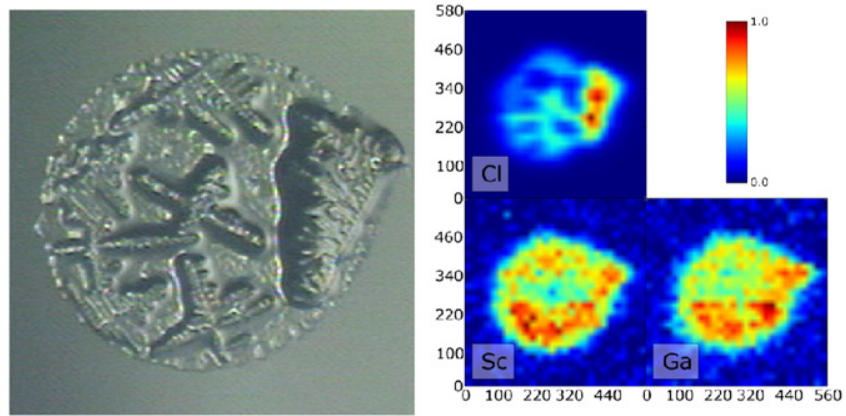

(b) Buffer on Plexiglas

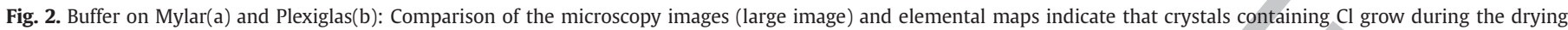
process.

thick quartz TXRF-reflectors to compensate for the high Comptonscattering background) to less than $1 \mathrm{~s}$ (in the case of insulin on Mylar).

\subsection{Evaluation}

TXRF-spectra were fitted with PyMca [25], yielding fluorescence intensities. Taking into account detector efficiencies absolute concentrations were then obtained based on the known Ga standard concentration. In the absence of matrix effects the Sc to Ga ratio as computed by PyMca should match the ratio used during sample preparation (mass ratio Sc:Ga $10 \mathrm{mg} / \mathrm{L}: 1 \mathrm{mg} / \mathrm{L}$, molar ratio $222.4 \mu \mathrm{M}: 14.3 \mu \mathrm{M}$ ). Any deviation from these values serves as an estimate for matrix effects.

XRF data were batch-fitted with AXIL [26], yielding raw fluorescence intensities which were used to generate elemental maps. Images were created by mapping the fluorescence intensities to a colour scale. To quantify the homogeneity of the elemental distributions we calculated 275 the Pearson correlation coefficients [27] $c_{P}$ of two elementals maps 276

$c_{\mathrm{P}}(X, Y)=\frac{\operatorname{cov}\left(\mathrm{map}_{X}, \mathrm{map}_{Y}\right)}{\sigma_{X} \sigma_{Y}}$

with map being the individual elemental maps and $\sigma$ their 278 standard deviation. All correlation coefficients in this work have 279 been calculated with respect to gallium $(Y=G a)$ if not otherwise 280 indicated.

This was applied to circular regions containing only the dried 282 residues. To compare all elemental maps easily, they were scaled to the 283 interval of [0.0,1.0] (only exception Fig. 4d: a very high density of Mn, Sc 284 and $\mathrm{Ga}$ in two small salt crystals would otherwise mask the "coffee 285 ring" formation). The figures showing the $\mu$ XRF results (Figs. 2-4) show 286 elemental maps of Sc and Ga as well as the most important elements 287
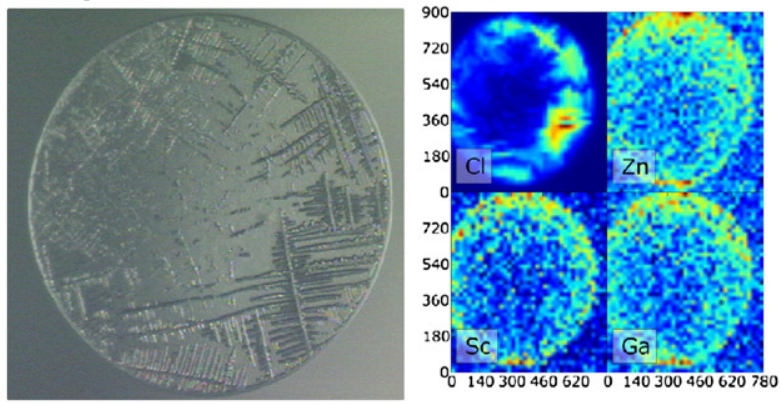

(b) hELAC1 on Plexiglas

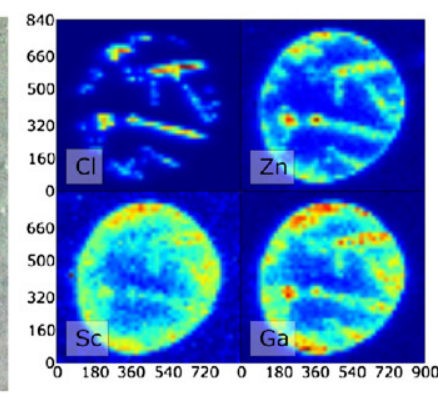

(a) hELAC1 on Mylar
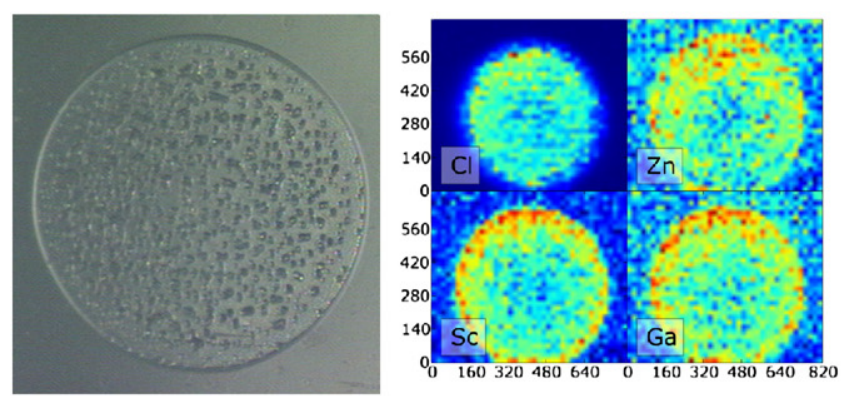

(c) hELAC1 on siliconized quartz
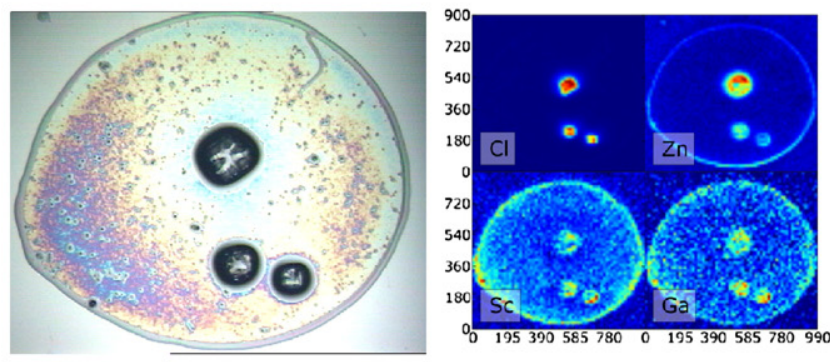

(d) hELAC1 on silicon

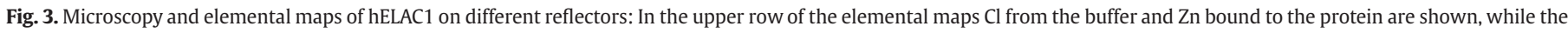

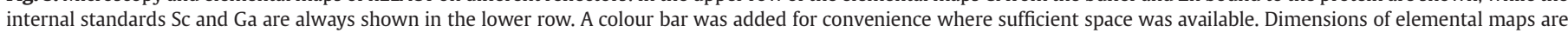
given in $\mu \mathrm{m}$. 

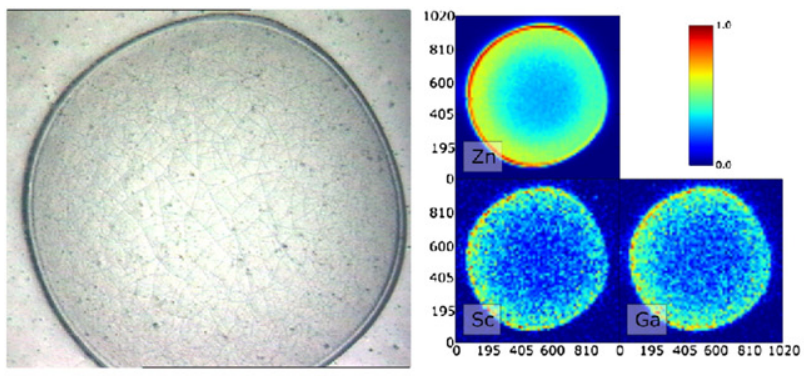

(a) Insulin on Mylar
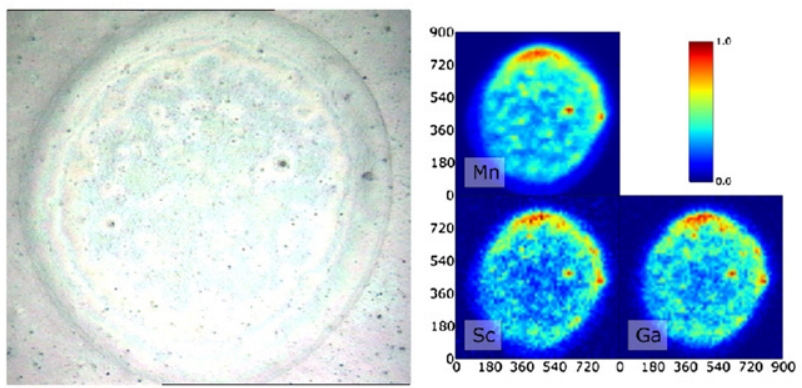

(c) Concanavalin A on Mylar
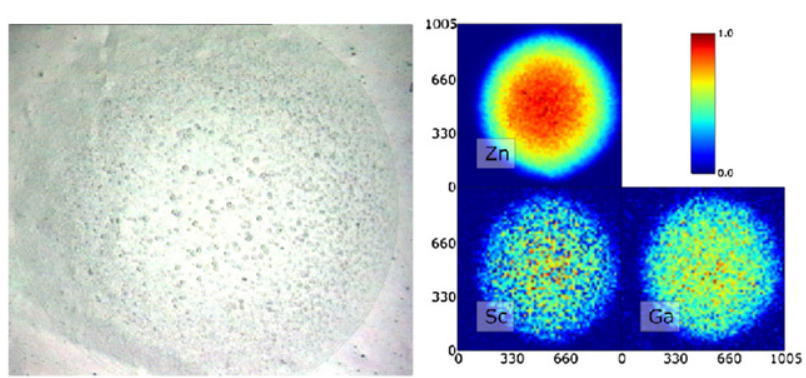

(e) Thermolysin on Mylar
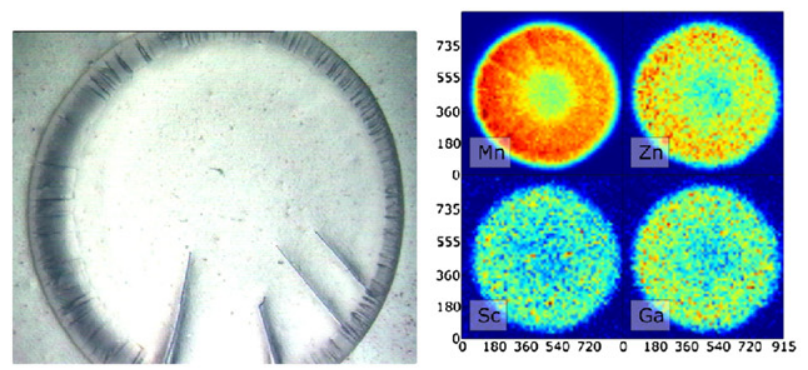

(g) Glucose isomerase on Mylar
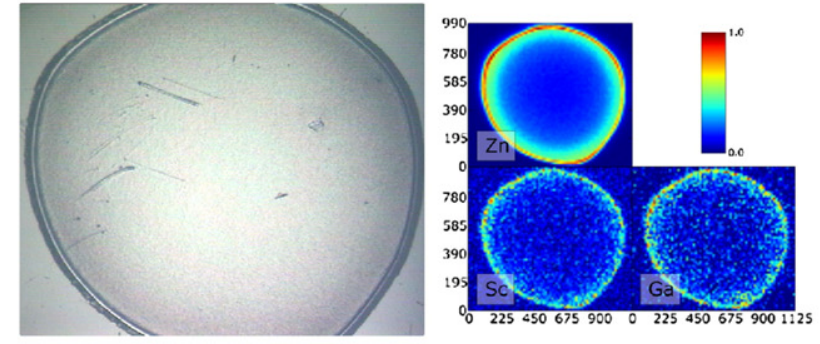

(b) Insulin on siliconized quartz
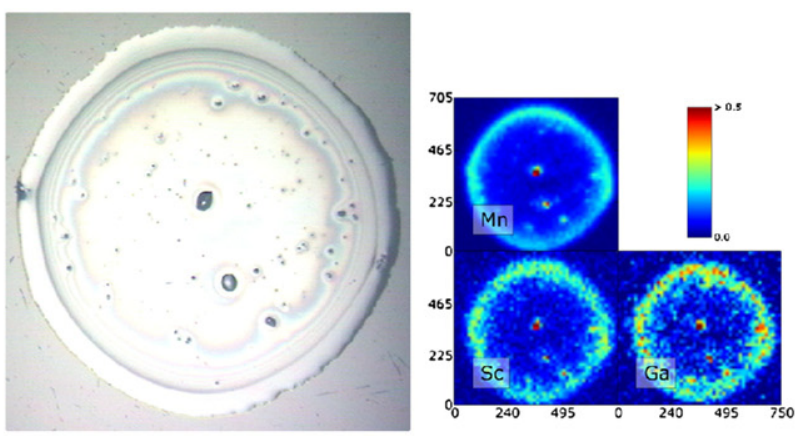

(d) Concanavalin A on siliconized quartz
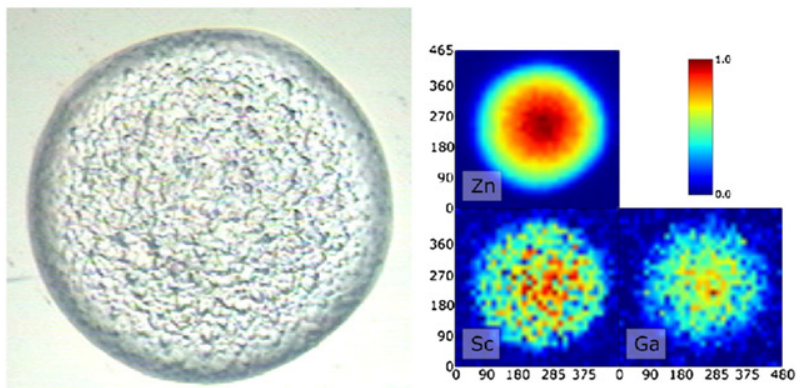

(f) Thermolysin on siliconized quartz
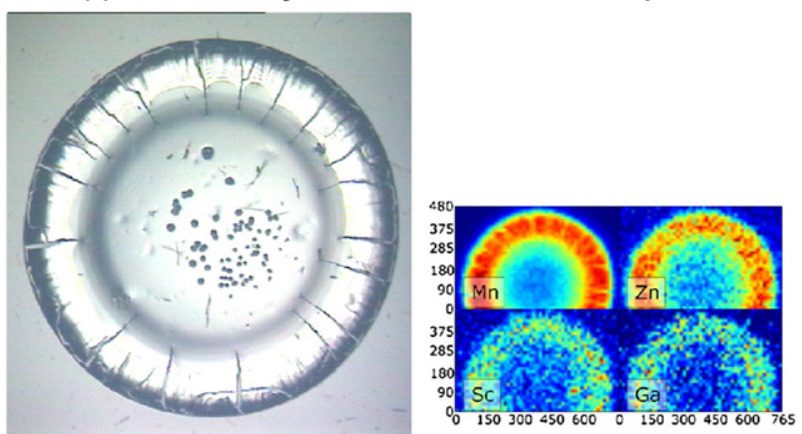

(h) Glucose isomerase on siliconized quartz

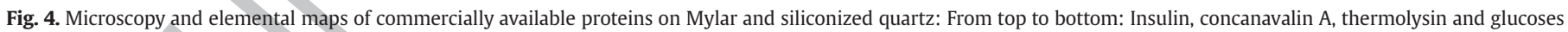

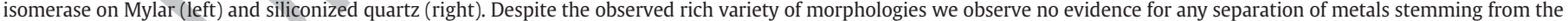
proteins compared to Sc or Ga from the internal standard.

for the corresponding sample, e.g. $\mathrm{Cl}$ for a buffer, $\mathrm{Zn}$ for a $\mathrm{Zn}$-binding protein like Insulin etc.

\section{Results and discussion}

In part I we examined the influence of several sample supports used in analytic methods on the drying properties of a metallo-enzyme (hELAC1) from our most recent study [15]. This is a challenging case because it requires glycerol in the buffer to prevent the loss of catalytic 294 activity upon freezing. But glycerol avoids complete drying, leading to 295 pronounced matrix effects in TXRF. Four different supports were 296 selected (Mylar, siliconized quartz, Plexiglas and silicon wafers) to 297 provide a cross-section of currently-used materials.

In part II we have examined several proteins both on Mylar and 299 siliconized quartz in order to elucidate the influence of the protein 300 properties on the formation of dried residues. 
Metal contents in TXRF samples are shown in $\mu \mathrm{M}$

\begin{tabular}{lrrrrrl}
\hline & \multicolumn{1}{l}{$\mathrm{Sc}$} & \multicolumn{1}{l}{$\mathrm{Mn}$} & \multicolumn{1}{l}{$\mathrm{Fe}$} & \multicolumn{1}{l}{$\mathrm{Ni}$} & \multicolumn{1}{l}{$\mathrm{Zn}$} & Ga (ref) \\
\hline Standard & $202.3(2)$ & $0.031(1)$ & $0.023(1)$ & $0.044(1)$ & $0.080(1)$ & 14.3 \\
Buffer+standard & $196(1)$ & $2.19(5)$ & $5.42(6)$ & $0.40(2)$ & $2.21(3)$ & 14.3 \\
$\begin{array}{l}\text { Protein +buffer + } \\
\quad \text { standard }\end{array}$ & $211(1)$ & $6.5(1)$ & $27.0(2)$ & $1.65(4)$ & $17.0(1)$ & 14.3 \\
Net protein content & - & $4.3(1)$ & $21.6(2)$ & $1.25(4)$ & $14.8(1)$ & - \\
\hline
\end{tabular}

The standard solution (first row) contains traces of metals $<0.1 \mu \mathrm{M}$. The metal concentrations found in the buffer sample (second row) can therefore be attributed to the gel filtration buffer, and have to be subtracted from the metal concentrations found in the protein sample (third row). The resulting net protein concentrations are displayed in the final row. Matrix effects are $\leq 10 \%$ for Sc (expected value of Sc is $222.4 \mu \mathrm{M}$ ) and therefore were neglected.
Table 3

t3.1

The correlation coefficients with respect to Ga for the pure standard and the buffer sample indicate no separation of Sc and Ga

\begin{tabular}{llllr} 
& Standard on Mylar & Buffer on Mylar & Buffer on Plexiglas & t3.2 \\
& & 0.74 .3 & \\
$\mathrm{Cl}$ & 1.00 & 0.98 & 0.84 & $\mathrm{t} 3.4$ \\
$\mathrm{Sc}$ & & & 0.94 & $\mathrm{t}$ \\
\hline
\end{tabular}

Microscopy images and elemental maps of hELAC1 on Mylar, 349 Plexiglas, siliconized quartz and silicon are displayed in Fig. 3(a)-(d), 350 respectively. Typical droplet sizes range from $\sim 700-1000 \mu \mathrm{m}$. Their 351 optical appearance is dominated by the rich variety of salt crystals 352 formed on the different substrates. 353

On Mylar (Fig. 3(a)) chlorine is predominantly built into needle-like 354 salt crystals. Protein bound $\mathrm{Zn}$ as well as the standards Sc and Ga are 355 incorporated into these crystals and the formation of a "coffee ring" is 356 observed [14]. In perfect agreement with the optical impression the 357 correlation coefficients of Sc and $\mathrm{Zn}$ with respect to $\mathrm{Ga}$ are close to 358 1.00 , proving almost complete linear correlation between the 359 elemental maps. Obviously standard and protein do not separate. $\mathrm{Cl} 360$ is only correlated with $\mathrm{Ga}$ at $c_{\mathrm{P}}=0.62$, most probably caused by its 361 absence in the "coffee ring".

362

Results are similar for hELAC1 on Plexiglas (Fig. 3(b)): needle-like 363 crystals containing $\mathrm{Cl}$, coffee-ring formation for protein bound $\mathrm{Zn}$ and 364 the standards. Due to the $45^{\circ}$ excitation geometry in $\mu \mathrm{XRF}$ the incident 365 beam penetrates deep into the sample supports, causing elastic and 366 inelastic scattering. While this is negligible for $0.6 \mu \mathrm{M}$ thick Mylar for 367 all other sample supports scattering caused an increased background. 368 This reduces the signal-to-noise ratio (SNR) significantly, despite a 369 fivefold increase of the data acquisition time per pixel. The decrease of 370 the SNR causes a systematic reduction of all correlation coefficients, 371 e.g. $c_{\mathrm{P}}\left(\mathrm{Sc}, \mathrm{Ga}\right.$ ) drops from 0.93 (Mylar) down to $0.50, c_{\mathrm{P}}(\mathrm{Zn}, \mathrm{Ga}) 372$ decreases from 0.94 to 0.56 . This drop does not dependent on the 373 choice of the standard used for the calculation. In fact, $c_{\mathrm{p}}(\mathrm{Zn}, \mathrm{Sc}) 374$ dropped also down to 0.50 , indicating that this change is purely 375 caused by the increased noise-level in the elemental maps. The similar 376 shifts of $c_{\mathrm{P}}(\mathrm{Zn}, \mathrm{Ga})$ vs. $c_{\mathrm{P}}(\mathrm{Sc}, \mathrm{Ga})$ indicate that no separation of 377 standard and metal from the protein occurs in the case of hELAC1 on 378 Plexiglas (Table 4).

In the case of hELAC1 on siliconized quartz $\mathrm{Cl}$ is distributed in 380 hundreds of small crystals $(<10 \mu \mathrm{m})$ homogenously throughout the 381 dried residue, with the exception of a $\sim 50 \mu$ m wide outer ring (Fig. 3(c)). 382 $\mathrm{Zn}$, Sc and $\mathrm{Ga}$ are predominantly present in this region, again forming a 383 "coffee-ring". No separation of standard and Zn stemming from the 384 protein can be observed neither by visual inspection of the elemental 385 maps nor by the correlation coefficients.

386

The last case, hELAC1 on silicon is slightly different: While one can 387 observe similar features as before (salt crystal formation with inclusion 388 of other elements and "coffee-ring" formation, see Fig. 3(d)), the 389 elemental maps of Ga and Sc show an increased overall density inside 390 the "coffee-ring", which is not the case for $\mathrm{Zn}$. This is in line with a 391 significantly lower $c_{\mathrm{P}}(\mathrm{Zn}, \mathrm{Ga})$ compared to $c_{\mathrm{P}}(\mathrm{Sc}, \mathrm{Ga})$, and therefore 392 resembles the only case in which we have found evidence for (partial) 393 separation of metals from the protein vs. standard.

The correlation coefficients for hELAC1 on Mylar, Plexiglas and siliconized quartz of Sc and $\mathrm{Zn}$ with respect to $\mathrm{Ga}$ are comparable, thereby indicating no separation of elements

\begin{tabular}{|c|c|c|c|c|}
\hline & Mylar & Plexiglas & Sil. quartz & Silicon \\
\hline$\overline{\mathrm{Cl}}$ & 0.62 & 0.31 & 0.32 & 0.36 \\
\hline $\mathrm{Zn}$ & 0.94 & 0.56 & 0.70 & 0.50 \\
\hline Sc & 0.93 & 0.50 & 0.72 & 0.61 \\
\hline
\end{tabular}

In the case of hELAC1 on silicon (last column) the correlation of $\mathrm{Zn}$ is decreased with respect to Sc, which could indicate a partial separation. 
For most supports standard vs. metal stemming from the protein show a similar distribution. Only in one case (hELAC1 on silicon) a partial separation has happened. Interestingly, the dominating effects governing the distribution of metals / standards are their inclusion into salt crystals and the formation of a "coffee-ring".

The nature of the substrate does significantly influence the morphology of the dried residue, esp. the size and distribution of salt crystals and the diameter of the residue $\left(d_{\text {quartz }}<d_{\text {Mylar }}<d_{\text {Plexi }}<d_{\text {silicon }}\right)$. From the perspective of an analytical method the morphology on quartz is most favourable: (I) Due to the siliconization of the surface the residue has the smallest diameter, which is important in order to fully illuminate the whole droplet with small X-ray beams, e.g. at the synchrotron (SR-TXRF). (II) Moreover, only for this support the drying resulted in the homogenous distribution of small sized salt crystals over the entire area.

\subsection{Part II: Influence of protein type and its buffer on dried residues}

To study the influence of protein properties on the formation of dried residues we analysed protein with low molecular weight (insulin) and high molecular weight (glucose isomerase), with different states of oligomerization (glucose isomerase is homotetrameric while thermolysin is homo-dimeric) and with different bound metal ions such as $\mathrm{Zn}$ (insulin) or Mn (glucose isomerase). We also investigated the influence of the protein solvent on the drying pattern (organic solvent for thermolysin vs inorganic solvent for the other proteins).

\subsection{1. $\mu \mathrm{X} R F$}

Upon drying Insulin formed very large dried residues $(\sim 1000 \mu \mathrm{m})$ on Mylar and siliconized quartz (Fig. 4(a)+(b)). Elemental maps show dominant formation of "coffee-rings". No elemental separation is found, neither in the elemental maps nor judging from the correlation coefficients (see Table 5).

Dried residues from Concanavalin $A$ (Fig. $4(\mathrm{c})+(\mathrm{d})$ ) are again dominated by "coffee-ring" formation: $\mathrm{Cl}$ can be detected primarily in an outer ring of $\sim 50 \mu \mathrm{m}$, while $\mathrm{Mn}$ associated with the protein and the standards is present in a second, inner ring. Again no elemental separation is evident.

Thermolysin (Fig. 4(e)+(f)) shows a completely different drying behaviour, independent of the substrate: Maximum concentrations are found in the centre for all elements, $\mathrm{Ca}$ and $\mathrm{Zn}$ associated with the protein as well as the standards. Thermolysin is the only protein examined which required DMSO to stay in solution; we expect that this different buffer causes the unusual drying behaviour. Nevertheless no separation is detected in the elementals maps or the correlation coefficients.

Glucose Isomerase (Fig. $4(\mathrm{~g})+(\mathrm{h})$ ), the largest protein examined, forms very broad "coffee-rings" $(\sim 200-300 \mu \mathrm{m})$. Again all elements co-localize on Mylar as well as on siliconized quartz.

This allows summarizing: Despite the different drying properties of the proteins examined in part II there is no evidence for a separation of metals associated with the protein and the standards, for any protein / substrate / buffer combination on Mylar or siliconized quartz.

Table 5

The correlation coefficients of $\mathrm{Zn}$ and $\mathrm{Mn}$ associated with different proteins are comparable to the correlation coefficients obtained for Sc, thereby indicating the lack of separation

\begin{tabular}{|c|c|c|c|c|c|c|c|c|}
\hline & \multicolumn{2}{|c|}{ Insulin } & \multicolumn{2}{|c|}{ Concanavalin A } & \multicolumn{2}{|c|}{ Thermolysin } & \multicolumn{2}{|c|}{ Glucose Isomerase } \\
\hline & Mylar & Quartz 04 & Mylar & Quartz 02 & Mylar & Quartz 01 & Mylar & Quartz 03 \\
\hline Mn & & & 0.95 & 0.74 & & & 0.87 & 0.70 \\
\hline $\mathrm{Zn}$ & 0.87 & 0.73 & & & 0.86 & 0.91 & 0.85 & 0.69 \\
\hline Sc & 0.77 & 0.60 & 0.92 & 0.72 & 0.64 & 0.79 & 0.74 & 0.52 \\
\hline
\end{tabular}

\section{Conclusions}

The drying of protein samples on all supports can lead to the 447 formation of salt crystals but typically not to a separation of an 448 internal standard from the metals stemming from the protein. These 449 effects vary depending on the reflector surface properties, as 450 examined for sample supports typically used in analytical methods 451 like TXRF and $\mu$ PIXE (Mylar, Plexiglas, siliconized quartz and silicon) 452 for the model protein hELAC1, which is known to form inhomoge- 453 neous dried residues. Under no conditions occurred a strong 454 separation of protein and internal standards. Only in one case, 455 hELAC1 on silicon, there is evidence for a small separation. This 456 undesirable feature of silicon surfaces strongly suggests to do further 457 work on siliconized silicon surfaces in order to reduce the affinity of 458 the standard for the surface. Among the other supports all our results 459 slightly favour siliconized quartz: It gives the smallest dried residue 460 diameter, the most homogenous distribution of trace metals and salt 461 crystals and showed no sign of any separation for any of the five 462 proteins examined. Siliconized quartz is in conclusion the sample 463 support of choice reducing sample inhomogeneities to a minimum. 464 Plexiglas is a good alternative, especially for the application of TXRF in 465 high-throughput, or if the detection of $\mathrm{Si}$ is important.

Moreover, on Mylar and siliconized quartz the influence of protein 467 properties was studied for insulin, concanavalin A, thermolysin and 468 glucose isomerase, which have different properties regarding e.g. 469 solubility, molecular weight, bound metal and oligomerization state. 470 While the morphology of dried residues varies significantly for the 471 different proteins there was no evidence for a separation of internal 472 standard vs. metal bound by the protein in any protein / reflector 473 combination.

Due to the strong morphologic variations of dried protein samples 475 matrix effects have to be considered. Foremost this requires a 476 possibility to detect and quantify matrix effects; for this purpose we 477 propose the application of two internal standards with at least 478 moderately different $Z$ and fluorescence energies with different 479 absorption properties. The high-Z element is used for the quantifica- 480 tion of other elements while the known concentration of the low-Z 481 element allows calculating the occurrence of an average matrix. For 482 proteins Sc and Ga are an ideal choice since they are rarely found in 483 proteins and bracket the most important 3d-metals. The implementa- 484 tion of two internal standards enables us to reliably detect and 485 quantify matrix effects; based on this we can correct for first order 486 matrix effects.

487

In total we only observed one possible case of separation of 488 standard vs. trace element which can be attributed to the choice of 489 reflector (silicon). Thus the general risk of a separation of internal 490 standard from metals associated with the protein is small and our 491 strategy to optimize the quantification of protein samples works 492 successfully:

(a) Sample inhomogeneities can be reduced by using siliconized 494 quartz sample supports.

(b) Matrix effects can be detected and quantified by implementing 496 two element standards from Sc and Ga. Further, a correction of 497 matrix effects in TXRF based on the assumption a complete lack 498 of separation seems feasible.

499

(c) The risk of a separation of elements of the internal standard vs. 500 metals stemming from the sample is small; apart from matrix 501 effects the remaining influence of the strong variance of dried 502 protein morphologies caused by salt crystal and "coffee ring" 503

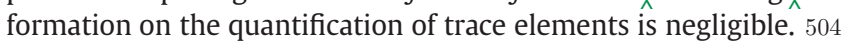

Preparation of protein samples using Sc and Ga as internal 505 standards is therefore straightforward, which allows benefiting from 506 the analytical power of TXRF for metalloproteins. Elaborate sample 507 decomposition is not necessary in general; instead a direct analysis of 508 protein samples is feasible. 


\section{Acknowledgements}

We gratefully acknowledge support by Gerald Falkenberg at beamline L, HASYLAB. We thankfully acknowledge the financial support from the European Union for BIOXHIT, contract number LSHG-GT 2003-503420.

\section{References}

[1] E. Pohl, J.C. Haller, A. Mijovilovich, W. Meyer-Klaucke, E. Garman, M.L. Vasil, Architecture of a protein central to iron homeostasis: crystal structure and spectroscopic analysis of the ferric uptake regulator, Mol. Microbiol. 47 (2003) 903-915.

[2] M.A. Fischbach, H.N. Lin, D.R. Liu, C.T. Walsh, How pathogenic bacteria evade mammalian sabotage in the battle for iron, Nat. Chem. Biol. 2 (2006) 132-138.

[3] M.E. Schaible, S.H.E. Kaufmann, Iron and microbial infection, Nat. Rev. Microbiol. 2 (2004) 946-953.

[4] H. Natal da Luz, D. Spemann, W. Meyer-Klaucke, W. Troger, Analysis of proteins by particle induced X-ray emission, Nucl. Instr. Meth. B 231 (2005) 308-314.

[5] R. Lill, U. Mühlenhoff, Maturation of iron-sulfur proteins in eukaryotes: mechanisms, connected processes, and diseases, Ann. Rev. Biochem. 77 (2008) 669-700.

[6] E. Garman, Leaving no element of doubt: analysis of proteins using microPIXE, Struct. Fold. Des. 7 (1999) R291-299.

[7] E.F. Garman, G.W. Grime, Elemental analysis of proteins by microPIXE, Prog. Biophys. Mol. Biol. 89 (2005) 173-205.

[8] A. Vogel, O. Schilling, M. Niecke, J. Bettmer, W. Meyer-Klaucke, ElaC encodes a novel binuclear zinc phosphodiesterase, J. Biol. Chem. 277 (2002) 29078-29085.

[9] R. Klockenkämper, Total-Reflection X-ray Fluorescence Analysis, John Wiley \& Sons, Inc., 1997

[10] T. Buhrke, S. Löscher, O. Lenz, E. Schlodder, I. Zebger, L.K. Andersen, P. Hildebrandt, W. Meyer-Klaucke, H. Dau, B. Friedrich, M. Haumann, Reduction of unusual ironsulfur clusters in the $\mathrm{H} 2$-sensing regulatory $\mathrm{Ni}$-Fe hydrogenase from Ralstonia Eutropha H16, J. Biol. Chem. (2005) 19488-19495.

[11] D. Barthelme, U. Scheele, S. Dinkelaker, A. Janoschka, F. MacMillan, S.-V. Albers, A.J.M. Driessen, M.S. Stagni, E. Bill, W. Meyer-Klaucke, V. Schunemann, R. Tampe, Structural organization of essential iron-sulfur clusters in the evolutionarily highly conserved ATP-binding cassette protein ABCE1, J. Biol. Chem. 282 (2007) 14598-14607.

[12] L. Fabry, S. Pahlke, L. Kotz, Accurate calibration of TXRF using microdroplet samples, Fresenius' J. Anal. Chem. 354 (1996) 266-270.

[13] T.C. Miller, G. Havrilla, Nanodroplets: a new method for dried spot preparation and analysis, X-Ray Spectrom. 33 (2004) 101-106.

[14] R.D. Deegan, O. Bakajin, T.F. Dupont, G. Huber, S.R. Nagel, T.A. Witten, Capillary flow as the cause of ring stains from dried liquid drops, Nature 389 (1997) 827-829.
[15] M.E.S. Achard, G. Wellenreuther, B. Kostelecky, U.E.A. Fittschen, W. Meyer-Klaucke, 551 Q2 $\mathrm{Zn}$ is not the only metal activating the Escherichia coli enzyme ElaC and its human 552 homologue ELAC1, both member of the metallo- $\beta$-lactamase superfamily, 553 submitted (2007)

[16] I. Dix, M. Sevvana, G. Bunkóczi, J.É. Debreczeni, G.M. Sheldrick, The EU BIOXHIT 555 standard test crystal, Acta Cryst. A 61 (2005) C147.

[17] E. Hough, L.K. Hansen, B. Birknes, K. Jynge, S. Hansen, A. Hordvik, C. Little, E. 557 Dodson, Z. Derewenda, High-resolution (1.5 A) crystal structure of phospholipase C 558 from Bacillus cereus, Nature 338 (1989) 357-360.

[18] J. Mueller-Dieckmann, The open-access high-throughput crystallization facility at 560 EMBL Hamburg, Acta Crystallogr., D 62 (2006) 1446-1452. 561

[19] H.L. Carrell, J.P. Glusker, V. Burger, F. Manfre, D. Tritsch, J.F. Biellmann, X-ray- 562 analysis of $\mathrm{D}$-xylose isomerase at 1.9 a-native enzyme in complex with substrate 563 and with a mechanism-designed inactivator, Proc. Natl. Acad. Sci. U. S. A. 86 (1989) 564 4440-4444.

[20] U.A. Ramagopal, M. Dauter, Z. Dauter, SAD manganese in two crystal forms of 566 glucose isomerase, Acta Crystallogr., D 59 (2003) 868-875. 567

[21] L. Redecke, M.v. Bergen, J. Clos, P.V. Konarev, D.I. Svergund, U.E.A. Fittschen, J.A.C. 568 Broekaert, O. Bruns, D. Georgieva, E. Mandelkow, N. Genov, C. Betzel, Structural 569 characterization of ß-sheeted oligomers formed on the pathway of oxidative prion 570 protein aggregation in vitro, J. Struct. Biol. 157 (2006) 308-320.

[22] G.P.C. Streli, P. Wobrauschek, C. Jokubonis, G. Falkenberg, G. Zaray, A new SR-TXRF 572 vacuum chamber for ultra-trace analysis at HASYLAB, Beamline L, X-Ray Spectrom. 573 34 (2005) 451-455.

[23] C. Streli, G. Pepponi, P. Wobrauschek, C. Jokubonis, G. Falkenberg, G. Záray, J. 575 Broekaert, U.E.A. Fittschen, B. Peschel, Recent results of Synchrotron radiation 576 induced TXRF at HASYLAB, Beamline L, Spectrochim. Acta Part B 61 (2006) 577 $1129-1134$.

[24] G. Falkenberg, O. Clauss, A. Swiderski, T, Tschentscher, Upgrade of the X-ray 579 fluorescence beamline at HASYLAB/DESY, X-Ray Spectrom. 30 (2001) 170-173. 580

[25] V.A. Sole, E. Papillon, M. Cotte, P. Walter, J. Susini, A multiplatform code for the 581 analysis of energy-dispersive X-ray fluorescence spectra, Spectrochim. Acta Part B 582 62 (2007) 63-68.

[26] B. Vekemans, K. Janssens, L. Vincze, F. Adams, P.V. Espen, Analysis of X-ray spectra 584 by iterative least squares (AXIL): New developments, X-Ray Spectrom. 23 (1994) 585 278-285.

[27] J.R. Green, Statistical Treatment of Experimental Data, Elsevier, 1978.

[28] O. Schilling, N. Wenzel, M. Naylor, A. Vogel, M. Ĉrowder, C. Makaroff, W. Meyer- 588 Klaucke, Flexible metal binding of the metallo-beta-lactamase domain: Glyoxalase 589 II incorporates iron, manganese, and zinc in vivo, Biochemistry 42 (2003) 590 11777-11786

29] N.F. Wenzel, A.L. Carenbauer, M.P. Pfiester, O. Schilling, W. Meyer-Klaucke, C.A. 592 Makaroff, M.W. Crowder, The binding of iron and zinc to glyoxalase II occurs 593 exclusively as di-metal centers and is unique within the metallo-beta-lactamase 594 family, J. Biol. Inorg. Chem. 9 (2004) 429-438. 